\title{
DINÂMICA EM SUPERFÍCIE, VOLUME, BIOMASSA E CARBONO NAS FLORESTAS PLANTADAS BRASILEIRAS: 1990-2016
}

\author{
DYNAMICS OF AREA, VOLUME, BIOMASS, AND CARBON IN THE BRAZILIAN PLANTED \\ FORESTS: 1990-2016
}

\author{
Carlos Roberto Sanquetta', Ana Paula Dalla Corte ${ }^{2}$, Allan Libanio Pelissari ${ }^{3}$, Margarida Tomé, \\ Greyce Charllyne Benedet Maas, ${ }^{5}$ Mateus Niroh Inoue Sanquetta ${ }^{6}$ \\ 1, 2, 3, 5, 6 Universidade Federal do Paraná, Curitiba, Paraná, Brasil - carlos_sanquetta@hotmail.com, \\ anapaulacorte@gmail.com, allanpelissari@gmail.com,greye.maas@gmail.com\& \\ mateus.sanquetta@gmail.com
}

${ }^{4}$ Universidade de Lisboa, Instituto Superior de Agronomia, Lisboa, Portugal-magatome@ulisboa.pt

RESUMO

\begin{abstract}
O objetivo do trabalho foi quantificar a dinâmica em superfície e dos estoques de volume de madeira, biomassa e carbono nas plantações florestais brasileiras. Dados sobre a extensão dessas florestas por diferentes instituições embasaram as estimativas para o período 1990-2016 para os principais gêneros utilizados em plantações florestais no Brasil. As produtividades foram simuladas com programas computacionais da EMBRAPA. Fatores de expansão de biomassa, razão de raízes, massa específica e teores de carbono de literatura foram aplicados. A área de florestas plantadas aumentou para 10,212 milhões ha (ano de 2016) em relação a área de 4,934 milhões ha (para o ano de 1990). O volume de madeira comercial cresceu de 774 milhões $\mathrm{m}^{3}$ em 1990 para 1,999 bilhão de $\mathrm{m}^{3}$ em 2016. A biomassa apresentou mudança de 457 milhões $t$ em 1990 a 1,246 bilhão $t$ em 2016. Os estoques de carbono apontaram 210 milhões t em 1990 e 575 milhões t em 2016. Eucalyptus contribuía com 60\% da área plantada em 1990, passando a 74\% em 2016 e sua participação em volume, biomassa e carbono aumentou de 52,57 e $58 \%$, em 1990, para 67, 71 e 71\% em 2016, respectivamente. O gênero Pinus pouco cresceu em área plantada, perdendo participação relativa. Outros gêneros têm participação modesta, mas vêm observando-se uma tendência de crescimento nos últimos anos. Concluiu-se que houve grande crescimento em área, volume, biomassa e carbono nas plantações florestais brasileiras nos 26 anos, em que as remoções de $\mathrm{CO}_{2}$ atmosférico equivalente nesse período foram da ordem de 1,338 bilhão $t$, as quais se devem pelo aumento da área plantada e pela maior produtividade dos povoamentos.
\end{abstract}

PALAVRAS-CHAVE: Eucalipto, Fatores de Expansão, Plantações, Pinus, Produtividade.

\section{ABSTRACT}

The dynamics of areas, volume, biomass, and carbon stocks in Brazilian forest plantations were quantified. Data on the extent of forests planted coming from different institutions were used to support the estimates for the period 1990-2016. The productivities were simulated using EMBRAPA's computer programs. Biomass expansion factors, root ratios, carbon contents and basic wood densities from literature were applied. The area of planted forests in 2016 is 10.212 million ha, compared to 4.934 million ha in 1990. The commercial wood volume increased from 774 million cubic meters in 1990 to 1.999 billion cubic meters in 2016. Biomass increased from 457 million tons in 1990 to 1.246 billion tons in 2016. The carbon showed 210 million tons stocked in 1990 against 575 million tons in 2016. Eucalyptus contributed with $60 \%$ of the planted area in 1990 and increased to 74\% in 2016, and its shares in volume, biomass and carbon were 52,57 , and $58 \%$ in 1990 , and 67,71 , and $71 \%$ in 2016 , respectively. Pinus presented small growth in area and has been losing relative participation. Other genera still show modest participation but have been experimenting growing in recent years. It was concluded that there was a great increase in area, volume, biomass, and carbon in the Brazilian forest plantations in the 26 years of the study and that the equivalent atmospheric $\mathrm{CO}_{2}$ removals in this period were 1.338 billion $t$, caused by the increase of the planted area and higher productivity.

KEYWORDS: Eucalypt, Expansion Factors, Plantations, Pine, Productivity. 


\section{INTRODUÇÃO}

É estrategicamente importante que o País detenha informações atualizadas e fidedignas sobre o estado e as tendências futuras de suas florestas, visando adotar políticas públicas que estimulem os investimentos no setor de base florestal e também norteiem as ações necessárias ao atendimento dos compromissos internacionais assumidos, notadamente no que tange à questão das mudanças climáticas.

A cada 5 anos, o Brasil aporta suas informações florestais à FAO (Food and Agriculture Organization of the United Nations, Organização das Nações Unidas para Alimentação e Agricultura). Nessa publicação, são reportados os estoques de volume de madeira em pé, biomassa e carbono, entre outros (FAO, 2014). As estatísticas do setor providas pelo SFB (Serviço Florestal Brasileiro) à $\mathrm{FAO}$ ainda se baseiam em dados secundários e indiretos, devido à carência de informações primárias. Essa lacuna poderá ser preenchida no futuro com a divulgação dos resultados do Inventário Florestal em execução no País (SFB, 2017).

As estatísticas florestais do País reportadas nos relatórios FRA (Forest Resources Assessment, Avaliação dos Recursos Florestais) (FAO, 2014) mostram uma evolução metodológica, devido ao grande número de pesquisas e publicações realizadas nos últimos anos pela academia brasileira (SILVEIRA et al., 2008; NOGUEIRA et al., 2008; SILVEIRA, 2010; HIGA et al., 2014; SILVA et al., 2015; AGUIAR et al., 2017). Melhorar a qualidade das informações é essencial para assegurar que os dados possam ser utilizados com segurança pelos usuários. Entre as informações de maior relevância estão os estoques volumétricos de madeira, de biomassa e carbono, bem como a sua dinâmica temporal.

Apesar de deter a segunda maior área de florestas naturais e figurar entre os que detêm as maiores áreas de florestas plantadas no mundo (FAO, 2014; PAYN et al., 2015) - as quais alcançam as maiores produtividades - 0 Brasil ainda perde espaço nesse setor para países com condições ambientais menos favoráveis e menores dimensões territoriais. Uma das razões que fazem esses países terem maior inserção na economia florestal mundial está na solidez e no detalhamento de suas informações florestais no longo prazo, compatível com o perfil da atividade.

Atualmente, as florestas plantadas respondem por mais $85 \%$ da madeira consumida no País (IBGE, 2016), o que corrobora para a importância de se ter informações atualizadas e confiáveis sobre seus estoques volumétricos. Desde os primórdios essas florestas foram estabelecidas com espécies exóticas de rápido crescimento, que se adaptaram bem às nossas condições ambientais e demonstraram ter excelentes aplicações tecnológicas. As principais essências cultivadas são dos gêneros Eucalyptus e Pinus (IBÁ, 2017), embora outras tenham despontado mais recentemente. Sua madeira serve para suprir à forte demanda das indústrias de papel e celulose, siderurgia, painéis, serrados, laminados e produtos beneficiados e acabados, entre outros.

A informação essencial para o planejamento da produção em florestas plantadas é o estoque volumétrico e sua evolução temporal. O volume é a variável básica e fundamental para que empresas e o setor florestal possam planejar e ordenar as disponibilidades presentes e futuras de madeira, a fim de atender às demandas do mercado e suprir a indústria.

As florestas, além de suprirem a matéria-prima para as indústrias de base florestal, também contribuem para a mitigação das alterações climáticas pelo fato de estocarem o carbono atmosférico em sua biomassa. Todavia, o Brasil tem se destacado negativamente nesse contexto, pois configura-se como um grande emissor de gases de efeito estufa (GEE) quando o assunto são as atividades de agricultura, florestas e outros usos da terra (AFOLU). Apesar disso, as atividades AFOLU podem desempenhar papel importante na mitigação do clima pelo Brasil (COHN et al., 2013), notadamente no concerne às atividades florestais.

As plantações florestais auxiliam na mitigação das alterações climáticas, pois estocam carbono em sua biomassa e nos produtos, e evitam emissões decorrentes de outros materiais potencialmente mais emissores em GEE. Com isso, o cultivo de florestas é uma alternativa para diminuir os efeitos das mudanças do clima e da degradação do ambiente em geral (SANQUETTA et al., 2011a). Ações adicionais envolvem medidas para evitar o desmatamento, promover o manejo florestal sustentável e incentivar o uso dessa matéria-prima em bens duráveis e nas construções, bem como substitutivo às energias fósseis.

Apesar de as florestas plantadas no Brasil possuírem destaque, as estimativas de biomassa e carbono nelas existentes ainda requerem refinamento substancial, visando diminuir o grau de incerteza das informações para atender às demandas internas do País e àquelas impostas pelos acordos dos quais o Brasil é signatário.

Este trabalho foi idealizado para colaborar nessa perspectiva e tem como objetivo quantificar a disponibilidade de volume de madeira comercial nas 
plantações florestais brasileiras e estimar, em um amplo espectro temporal (26 anos), os seus estoques de biomassa e carbono, visando evidenciar o papel destas na mitigação das emissões de GEE no País.

Sendo assim, o objetivo do trabalho foi quantificar a dinâmica em superfície e dos estoques de volume de madeira, biomassa e carbono nas plantações florestais brasileiras.

\section{MATERIAL E MÉTODOS}

\section{Extensão das Florestas}

Três fontes sobre a extensão das florestas plantadas no Brasil foram utilizadas:

1. Dados da Produção da Extração Vegetal e da Silvicultura - PEVS (IBGE, 2016);

2. Relatório 2017 da Indústria Brasileira de Árvores (IBÁ, 2017); e

3. Global Forest Resources Assessment FRA2015, Brazil (FAO, 2014).

Os dados da primeira fonte referem-se ao período 2014-2016 e são aqueles considerados oficiais, pois foram produzidos e publicados pela autarquia responsável pelas estatísticas oficiais do País. Os da segunda referência correspondem ao período 2010-2016 e são produzidos pela maior entidade representante das empresas de base florestal do Brasil. A terceira fonte consiste do relatório apresentado pelo SFB à FAO, que o edita e publica, assim como faz para a maioria dos países, cujas áreas se baseiam nas informações reportadas pela antiga ABRAF (Associação das Empresas de Base Florestal), atual IBÁ. Cabe destacar que não há um mapeamento completo e contínuo das plantações florestais brasileiras utilizando sensoriamento remoto. Portanto, o que se tem em todas as fontes citadas são estimativas e não determinações reais de área.

Para efeito deste trabalho, foram adotadas as áreas reportadas pelo IBGE de 2014 a 2016 (IBGE, 2016), exceto no caso das outras espécies ou gêneros (que não Eucalyptus e Pinus), cuja área informada pelo IBÁ é maior que a do IBGE. Em outras palavras, sempre se optou pela maior área, até porque o IBÁ possui controle apenas sobre seus associados, desconsiderando os produtores independentes. Para o período 2010 a 2013 foram usadas as áreas informadas pelo IBÁ (IBÁ, 2017) e para demais anos anteriores adotaram-se as áreas informadas no FRA2015 (FAO, 2014).

\section{Estimativa do Volume de Madeira}

Para estimar os volumes comerciais de madeira (considerando até $4 \mathrm{~cm}$ de diâmetro de ponta fina para todas as espécies/gêneros), nas plantações florestais brasileiras, foram utilizados dados de produtividade gerados a partir dos simuladores desenvolvidos pela EMBRAPA (2018) (baixados em 08/01/2018), quais sejam:

1. SISEUCALIPTO: programa desenvolvido para espécies do gênero Eucalyptus. Neste trabalho, usou-se a versão Eucalyptus grandis / Eucalyptus urograndis, uma vez que essas são as principais espécies do gênero no País. Todos os parâmetros de entrada do programa foram mantidos default, ou seja, aqueles que vêm na versão original do programa. Foram simuladas as produtividades por hectare para os índices de sítio 29, 31 e $33 \mathrm{~m}$ de altura dominante na idade de 7 anos (índice de sítio), representando os sítios de baixa, média e alta produtividade, respectivamente. As simulações foram feitas com densidade inicial de 1.111 árvores.ha-1 ${ }^{-1}$, sem desbaste e assumiu-se que a rotação silvicultural é de 7 anos;

2. SISPINUS: programa desenvolvido para espécies do gênero Pinus. Neste trabalho usou-se a versão Pinus taeda L., uma vez que essa é a principal espécie plantada do gênero no País. Todos os parâmetros de entrada do programa foram mantidos default e foram simuladas as produtividades para os índices de sítio 21, 23 e $25 \mathrm{~m}$ de altura dominante na idade de 15 anos. As simulações foram feitas com densidade inicial de 1.111 árvores.ha $^{-1}$, $50 \%$ sem desbaste e $50 \%$ com um desbaste na idade 8 anos (remoção de $50 \%$ da densidade inicial, sistemático na 6a linha, seguido de seletivo). Assumiu-se também que a rotação silvicultural é de 20 anos;

3. SISTECA: programa desenvolvido para Tectona grandis L. f. Todos os parâmetros de entrada do programa foram mantidos default e foram simuladas as produtividades para os índices de sítio 18, 20 e $22 \mathrm{~m}$ de altura dominante na idade de 15 anos. As simulações foram feitas com densidade inicial de 1.250 árvores.ha ${ }^{-1}$, com um desbaste na idade 8 anos (remoção de $50 \%$ da densidade inicial, somente seletivo) e assumiu-se que a rotação silvicultural é de 15 anos;

4. SISACACIA: programa desenvolvido para acácia-negra (Acacia mearnsii De. Wild.). Todos os parâmetros de entrada do programa foram mantidos default e foram simuladas as produtividades para os índices de sítio 16, 18 e $20 \mathrm{~m}$ de altura dominante na idade de 7 anos. As 
simulações foram feitas com densidade inicial de 2.000 árvores.ha ${ }^{-1}$, sem desbaste e assumiu-se que a rotação silvicultural é de 7 anos.

Apesar dos volumes comerciais terem sido levados em consideração para as análises desse trabalho, optou-se também por apresentar os incrementos médios anuais (IMA) com a finalidade de representar em termos médios, as produções máximas possíveis em cada cenário. Tais produções estão apresentadas na Tabela 1.

Tabela 1. Produtividades volumétricas (IMA) estimadas paras as plantações florestais brasileiras

\begin{tabular}{cccc}
\hline \multirow{2}{*}{ Espécie } & \multicolumn{3}{c}{ Produtividade $\left(\mathbf{m}^{\mathbf{3}} \cdot \mathbf{h a}^{-1}\right.$.ano } \\
\cline { 2 - 4 } & Baixa & Média & Alta \\
\hline Eucalyptus* & 36 & 42 & 48 \\
P. taeda & 22 & 27 & 32 \\
T. grandis & 13 & 17 & 22 \\
A. mearnsii & 20 & 25 & 31 \\
\hline
\end{tabular}

*E. grandis/urograndis

Como não se dispõe de dados sobre a estrutura etária das plantações florestais no Brasil assumiu-se uma distribuição retangular uniforme, ou seja, que todas as classes etárias de 1 ano até a idade de rotação têm a mesma área. Assim, a área plantada foi dividida em $n$ partes correspondentes a cada idade, de zero (em corte raso ou plantio) até a idade de rotação. Uma classe etária adicional foi criada para representar eventuais povoamentos com idades superiores à idade de rotação, com idade média de 12 anos para Eucalyptus, 25 anos para Pinus, 20 anos para Tectona e 10 anos para Acacia.

Os volumes de madeira por hectare advindos dos simuladores foram então multiplicados pelas áreas de cada espécie/gênero. No caso das outras espécies, foi considerado que $50 \%$ encontravam-se em regime para uso múltiplo (representado por T. grandis) e 50\% em regime de manejo para processo (representado por $A$ mearnsii).

Para o período 1990-2000 adotou-se a produtividade mais baixa (menor índice de sítio), considerando que no passado a mesma era menor em função do menor nível tecnológico adotado. Para 2000-2010, efetuou-se a média aritmética da produtividade média com a menor produtividade, e para 2011 em diante adotou-se a média da produtividade média e a alta, expressando, assim, o maior grau tecnológico aplicado nos últimos anos.

\section{Estimativa da Biomassa}

As biomassas secas totais (acima e abaixo do solo) estocadas nas plantações florestais foram estimadas a partir da aplicação das correspondentes massas específicas básicas $(M E B)$ e dos fatores de expansão da biomassa (FEB) para a obtenção da biomassa acima do solo e da razão de raízes (root-to-shoot ratio) $(R)$ para a estimativa da biomassa subterrânea. MEB converte o volume do fuste (tronco) em massa ou peso (t), $F E B$ expande a massa do fuste para toda a parte aérea e $R$ considera a fração de raízes abaixo do solo. Para calcular a biomassa total foi aplicada a equação multiplicada pelas áreas das plantações em cada ano considerado:

$$
W=V^{*} M E B^{*} F E B^{*}(1+R)
$$

Em que: $W=$ biomassa seca total acima e abaixo do solo (t); $V=$ volume comercial dos fustes $\left(\mathrm{m}^{3}\right)$; e $M E B=$ massa específica básica $\left(\mathrm{t} . \mathrm{m}^{-3}\right)$.

$$
F E B=\frac{W_{\text {aérea }}}{W_{\text {fuste }}}
$$

Em que: $W_{\text {aérea }}=$ biomassa seca aérea ou acima do solo (t); $W_{\text {fuste }}=$ biomassa seca dos fustes $(\mathrm{t})=V^{*} M E B$; e $F E B=$ fator de expansão da biomassa $\left(t . t^{-1}\right)$.

$$
R=\frac{W_{\text {subterrânea }}}{W_{\text {aérea }}}
$$

Em que: $W_{\text {subterrânea }}=$ biomassa seca abaixo do solo ou subterrânea (t); e $R=$ razão de raízes $\left(\mathrm{t} . \mathrm{t}^{-1}\right)$.

Os valores empregados neste trabalho foram obtidos da literatura correlata (Tabela 2). Em muitos casos, os valores foram únicos para cada espécie, e em outros (quando existiam informações) houve diferenciação por idade, com as variações mostradas no corpo da tabela.

Tabela 2. MEB, FEB, $R$ e $T C$ para as essências florestais plantadas do Brasil tomadas da literatura correlata

\begin{tabular}{ccccc}
\hline Gênero & MEB $\left(\mathbf{t} \cdot \mathbf{m}^{-\mathbf{3}}\right)$ & $\boldsymbol{F E B}\left(\mathbf{t} . \mathbf{t}^{-\mathbf{1}}\right)$ & $\boldsymbol{R}\left(\mathbf{t} . \mathbf{t}^{-\mathbf{1}}\right)$ & $\boldsymbol{T C}\left(\mathbf{g} \cdot \mathbf{g}^{-\mathbf{1}}\right)$ \\
\hline Eucalyptus & 0,5090 & $1,0365-$ & 0,1700 & 0,4630 \\
& $0,3223-$ & $1,0902-$ & $0,1097-$ & 0,4536 \\
Pinus & 0,3782 & 2,5463 & 0,5830 & \\
T. grandis & 0,4750 & 1,4100 & 0,4800 & 0,5000 \\
A. mearnsii & 0,6345 & 1,2468 & 0,1309 & 0,4410 \\
\hline
\end{tabular}

MEB: massa específica básica da madeira (RIBEIRO \& ZANI FILHO, 1993; SETTE JR. et al., 2005; SANQUETTA et al., 2016; SANQUETTA et al., 2013).

FEB: fator de expansão de biomassa (SILVA et al., 2015; SANQUETTA et al., 2011b; ALMEIDA et al., 2010; SANQUETTA et al., 2014).

$R$ : razão de raízes (RIBEIRO et al., 2015; SANQUETTA et al., 2011b; SETTE JR. et al., 2005; DALLAGNOL et al., 2011).

TC: teor de carbono: (RIBEIRO et al., 2015; DALLAGNOL et al., 2011; ALMEIDA et al., 2010; SANQUETTA et al., 2014). 


\section{Estimativa dos Estoques de Carbono}

Para estimar os estoques de carbono foram tomados os valores de biomassa multiplicados pelos respectivos teores de carbono (TC) para cada espécie/gênero considerado.

$$
C=W^{*} T C
$$

Em que: $C=$ de carbono na biomassa total, acima e abaixo do solo (t); e $W=$ biomassa seca total acima e abaixo do solo $(t)$.

Para estimar as remoções em $\mathrm{CO}_{2} e q$ (dióxido de carbono equivalente) os estoques de carbono foram convertidos por estequiometria, assumindo as massas atômicas: $C=12$ e $O=16$, portanto $\mathrm{CO}_{2}=44$ :

$$
\mathrm{CO}_{2} e q=C * \frac{44}{12}
$$

Em que: $\mathrm{CO}_{2} e q=$ dióxido de carbono equivalente.

\section{RESULTADOS E DISCUSSÃO}

\section{Extensão das Florestas Plantadas}

A área de florestas plantadas no Brasil cresceu de 4,934 para 10,212 milhões de hectares no período 1990 a 2016, o que significa que ela mais que dobrou nesse interstício temporal (Tabela 3 e Figura 1). O Eucalyptus sempre foi o mais plantado no Brasil, e a sua participação relativa aumentou, passando de 60\% em 1990 para $74 \%$ em 2016. Isso ocorreu pelo aumento expressivo de sua área plantada comparado ao Pinus, que apresentou um crescimento bem menor (de 17\%) na área plantada, e também pela modesta participação das outras espécies.

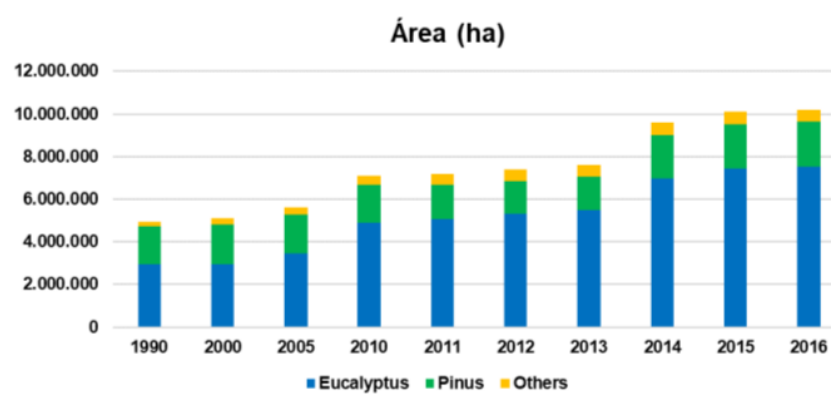

Figura 1. Área de florestas plantadas no Brasil.

Fonte: adaptado de FAO (2014), IBGE (2016) e IBÁ (2017).

As outras espécies, apesar de sua pequena participação na extensão total das florestas plantadas, vêm incrementando sua participação, de 4\% em 1990 para 6\% em 2016. O gênero Pinus vem perdendo espaço, uma vez que correspondia a $36 \%$ da área plantada em 1990 e reduziu-se a $20 \%$ em 2016, ou seja, uma expressiva diminuição percentual.

A década de 1960 marcou o início da política de incentivos fiscais do Governo Federal para o reflorestamento, a qual ganhou grande dimensão na década de 1970, tendo sido interrompida no ano de 1988 (ANTONANGELO \& BACHA, 1998). Estima-se que houve um salto abrupto na área plantada com espécies florestais, de 500 mil hectares na década ao final 1960, passando a 2,6 milhões ha em 1975 e 6 milhões ha em 1985 (BACHA, 1992).

Com o fim da política de incentivos fiscais houve uma imediata redução na área plantada/reformada, ocorrendo uma retomada dos plantios a partir de 1995 com uso de recursos privados, e o efeito disso foi que em 1990 a área de florestas plantadas caiu para 5 milhões ha. Portanto, o Brasil passou por altos e baixos até consolidar sua tendência de crescimento nos últimos 26 anos em termos de área plantada com florestas. Os últimos anos têm sido marcados por aumentos contínuos na área de florestas plantadas.

Desde o início dos plantios florestais no Brasil até os dias de hoje não houve nenhum levantamento primário realizado pelo poder público ou privado que cobrisse toda a área de florestas plantadas do Brasil, nem mesmo pelo Inventário Florestal Nacional encerrado entre o final da década de 1970 e o início da década de 1980.

O Inventário Florestal Nacional também não contempla tal empreitada, mas busca meios para viabilizar a obtenção de informações acuradas e atualizadas também para as florestas plantadas, que embora diminutas em comparação às florestas nativas, são muito importantes do ponto de vista socioeconômico. A consequência da falta de dados reais da cobertura florestal plantada a partir de sensoriamento remoto e mensuração em campo é o uso de aproximações e estimativas, que persiste e parece não ter perspectivas de mudar, apesar de algumas iniciativas isoladas. Negativo em termos de políticas públicas, ruim para o investidor florestal e para o desenvolvimento socioeconômico do País.

A expansão da área de florestas plantadas pode ser considerada, de um lado, muito positiva, pois coincide com o advento da construção e da operação de grandes fábricas de celulose e papel em Mato Grosso do Sul (MS), Bahia, Maranhão, entre outros, permitindo crescimento econômico, grandes oportunidades, empregos e renda nessas regiões menos tradicionais para a indústria de base florestal. 
Por outro lado, a expansão mal planejada da implantação de florestas produtivas, sobretudo em regiões pioneiras, pode trazer preocupações e prejuízos. Em MS, onde a expansão da eucaliptocultura se dá de forma mais icônica (outros Estados também apresentaram forte expansão), atualmente o preço da madeira não remunera o produto de forma adequada, o que, a persistir, levará muitos produtores a desistir da atividade. Isso parece emblemático no Brasil e tal situação na atualidade em MS não é uma exceção e sim a repaginação de fatos históricos.

Questões sociais, culturais e legais também são fundamentais nesse processo, vide exemplo de alguns investimentos frustrados na chamada "Metade Sul do Rio Grande do Sul" (LERRER \& WILKINSON, 2016). Expansões da base florestal devem ser precedidas de um planejamento competente, conhecimento profundo da cadeia produtiva (interna e externa), uso de informações científicas e aplicação de tecnologias apropriadas para manejo das florestas, além de considerar as externalidades socioambientais, os riscos e as incertezas de um país de instabilidades frequentes.

A expansão das áreas de florestas plantadas com outras espécies não tradicionais também é importante para diversificar a oferta e atender a outras demandas industriais e de mercado. O aumento da área de outras espécies possibilita maior diversificação de matériasprimas e produtos de base florestal. Contudo é importante que os pacotes tecnológicos para a silvicultura e manejo dessas espécies sejam consolidados para garantir economicidade do negócio ao produtor e crescimento sustentável da área plantada com essas espécies alternativas.

Tabela 3. Extensão das florestas plantadas no Brasil segundo diferentes fontes e valores harmonizados

\begin{tabular}{|c|c|c|c|c|c|c|c|c|c|c|c|}
\hline \multirow{2}{*}{ Fonte } & \multirow{2}{*}{ Gênero } & \multicolumn{10}{|c|}{ Ano } \\
\hline & & 1990 & 2000 & 2005 & 2010 & 2011 & 2012 & 2013 & 2014 & 2015 & 2016 \\
\hline \multirow{3}{*}{ IBGE (2017) } & Eucalyptus & - & - & - & - & - & - & - & 6.952 .509 & 7.444 .625 & 7.543 .707 \\
\hline & Outros & - & - & - & - & - & - & - & 364.998 & 427.762 & 400.207 \\
\hline & Total & - & - & - & - & - & - & - & 9.366 .741 & 9.937 .947 & 10.023 .076 \\
\hline \multirow{4}{*}{ IBÁ (2017) } & Eucalyptus & - & - & - & 4.900 .949 & 5.049 .714 & 5.304 .164 & 5.473 .176 & 5.558 .653 & 5.630 .606 & 5.673 .783 \\
\hline & Pinus & - & - & - & 1.756 .359 & 1.641 .892 & 1.562 .782 & 1.570 .146 & 1.588 .997 & 1.581 .239 & 1.584 .332 \\
\hline & Outros & - & - & - & 462.390 & 489.282 & 521.131 & 557.652 & 588.521 & 589.201 & 589.361 \\
\hline & Total & - & - & - & 7.121.708 & 7.182 .899 & 7.390 .089 & 7.602 .987 & 7.738 .185 & 7.803 .061 & 7.849 .492 \\
\hline \multirow{4}{*}{ FAO (2014) } & Eucalyptus & 2.964 .000 & 2.965 .880 & 3.462 .719 & 4.754 .334 & 4.873 .952 & 5.102 .030 & - & - & - & - \\
\hline & Pinus & 1.769 .000 & 1.840 .050 & 1.831 .485 & 1.756 .359 & 1.641 .892 & 1.562 .782 & - & - & - & - \\
\hline & Outros & 201.141 & 319.976 & 326.176 & 462.390 & 489.282 & 521.131 & - & - & - & - \\
\hline & Total & 4.984 .141 & 5.125 .906 & 5.620 .380 & 6.973 .083 & 7.005 .126 & 7.185 .943 & - & - & 7.735 .772 & - \\
\hline \multirow{3}{*}{ Harmonizada } & Pinus & 1.769 .000 & 1.840 .050 & 1.831 .485 & 1.756 .359 & 1.641 .892 & 1.562 .782 & 1.570 .146 & 2.049 .234 & 2.065 .560 & 2.079 .162 \\
\hline & Outros & 201.141 & 319.976 & 326.176 & 462.390 & 489.282 & 521.131 & 557.652 & 588.521 & 589.201 & 589.361 \\
\hline & Total & 4.984.141 & 5.125 .906 & 5.620 .380 & 7.121.708 & 7.182 .899 & 7.390 .089 & 7.602 .987 & 9.590 .264 & 10.099 .386 & 10.212 .230 \\
\hline
\end{tabular}

\section{Volume de Madeira nas Florestas Plantadas}

O volume de madeira comercial cresceu de 774 milhões $\mathrm{m}^{3}$ em 1990 para 1,999 bilhão de $\mathrm{m}^{3}$ em 2016, ou seja, um aumento de $158 \%$. Esse volume correspondente à parte comercial dos troncos a partir de um diâmetro mínimo de $4 \mathrm{~cm}$ na ponta fina com casca. O gênero Eucalyptus respondia por $52 \%$ do volume existente em 1990 e passou a 67\% em 2016. Por sua vez, o gênero Pinus diminuiu drasticamente sua participação, de $46 \%$ em 1990 para 28\% em 2016. As outras espécies aumentaram de $3 \%$ para $4 \%$. Dois fatores afetaram o crescimento do volume estocado de madeira, nomeadamente o aumento na superfície plantada e a maior produtividade alcançada nas plantações nos últimos anos. Portanto, o aumento em volume foi proporcionalmente mais expressivo que o aumento em área de plantio (Figura 2).

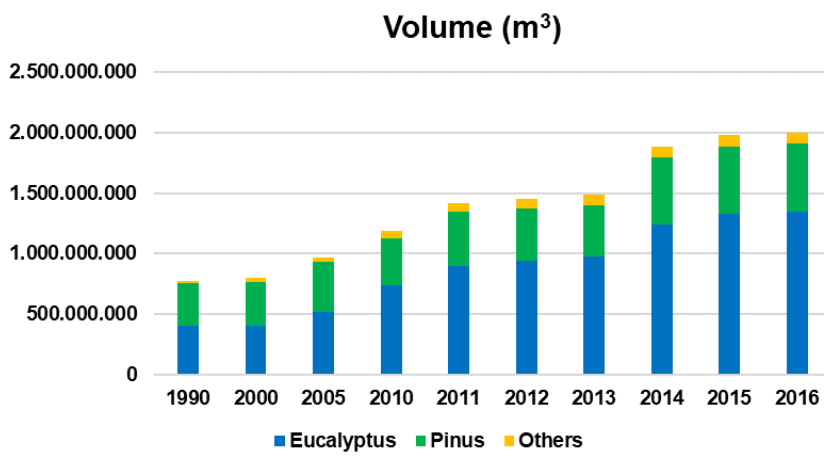

Figura 2. Volume de madeira nas florestas plantadas do Brasil. 
O estoque volumétrico nas florestas plantadas estimado neste trabalho em 2016 - de 1.999 milhões m $^{3}$ (em 2015 foi estimado em 1.977 milhões $\mathrm{m}^{3}$ ) - aproximase daquele reportado no FRA2015 (FAO, 2014), que é de 2,107 bilhões $\mathrm{m}^{3}$, ou seja, há uma diferença de $5,4 \%$ entre ambos os levantamentos. Entretanto, o relatório da FAO faz alusão ao cálculo do volume como sendo o total obtido a partir de árvores acima de $10 \mathrm{~cm}$ de diâmetro à altura do peito, com casca, desconsiderando um limite diamétrico na ponta fina e volume dos galhos. Por conseguinte, essa diferença pode ser produto dos distintos critérios adotados nos estudos. Há que se considerar a diferença em termos de área entre o presente estudo, que utilizou dados do IBGE (2016), ou seja, 10,2 milhões ha contra 7,7 milhões ha reportados no FRA2015.

No ano de 2016 foram produzidos cerca de 185 milhões $\mathrm{m}^{3}$ de madeira roliça das plantações florestais brasileiras, dos quais 140,5 milhões $\mathrm{m}^{3}$ de eucalipto, 39,3 milhões $\mathrm{m}^{3}$ de pinus e 5,4 milhões $\mathrm{m}^{3}$ de outras espécies (IBGE, 2016). Admitindo que esse valor se aproxima do consumo anual, pois o grande volume exportado pelo Brasil é de toras com algum tipo de processamento, sendo assim, o estoque volumétrico existente seria suficiente para cerca de 11 anos, em termos médios.

Especificamente, esse período seria de 10,14 e 16 anos, respectivamente para eucalipto, pinus e as outras espécies. Isso representa mais ou menos o período de uma rotação silvicultural, não havendo grandes folgas para eventuais aumentos expressivos de produção. No caso do eucalipto há uma reserva volumétrica que supera a rotação típica em regimes de manejo para processo, usualmente 7 anos. Tais informações são relevantes para o planejamento setorial e para a atração de investimentos.

\section{Biomassa Estocada nas Florestas Plantadas}

O estoque de biomassa nas florestas plantadas do Brasil também apresentou crescimento, passando de 457 milhões $t$ em 1990 a 1,246 milhões $t$ em 2016, ou seja, $172 \%$ de acréscimo. Isso se refere à biomassa seca total (aérea + subterrânea) estocada nos troncos, galhos, folhas e raízes das árvores e exclui a necromassa (tecidos mortos) aderida ou caída sobre o solo e o próprio carbono orgânico no solo. O gênero Eucalyptus participava com 57\% desse montante em 1990 e passou a 71\% em 2016, enquanto Pinus recuou de $38 \%$ para $23 \%$ no período considerado. Já as outras espécies tiveram aumento, de $4 \%$ para $7 \%$ nesse período (Figura 3).

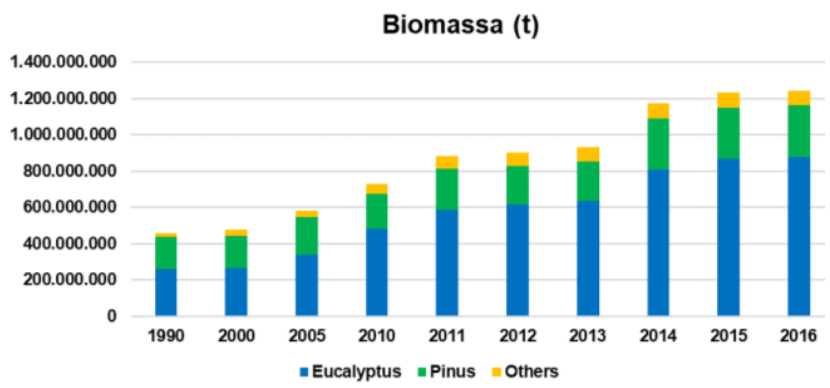

Figura 3. Biomassa seca total nas florestas plantadas do Brasil.

Observou-se uma diferença importante entre os resultados ora apresentados e aqueles reportados no FRA2015 no que concerne à biomassa. A diferença do valor de 2016 deste estudo com o do FRA2015 é de mais de $50 \%$, isto é, de 1,246 milhões t neste estudo (1.232 milhões $t$ em 2015) para de 1,896 milhões $t$ no FRA, apesar da área menor aplicada naquele estudo em relação à presente. A causa determinante dessa diferença possivelmente esteja nas abordagens metodológicas e/ou nos valores de $M E B, F E B, R$. Não há menção de como foram feitos os cálculos de biomassa nas plantações no FRA2015 nem são apresentados os valores correspondentes de $M E B, F E B$ e $R$.

Neste trabalho os valores utilizados são aqueles mostrados na Tabela 2. Como os valores de MEB para a maioria das espécies plantadas no Brasil são inferiores a $0,5 \mathrm{~g} . \mathrm{cm}^{-3}$, somente valores bem mais altos de FEB e $R$ (o que não é esperado) que os referenciados neste estudo poderiam aproximar a relação entre volume e biomassa de 1. Isso demonstra a necessidade de mais pesquisas sobre esses fatores e sua sistematização em quantificações de biomassa e carbono em larga escala.

\section{Carbono Estocado nas Florestas Plantadas e Remoções de $\mathrm{CO}_{2}$}

A dinâmica dos estoques de carbono na biomassa acima e abaixo do solo nas florestas plantadas do Brasil apontou um aumento de 210 milhões t em 1990 para 575 milhões t em 2016, ou seja, 73\% de acréscimo. Eucalyptus contribuía com $58 \%$ desse montante em 1990 e passou a $71 \%$ em 2016, enquanto Pinus diminuiu de $38 \%$ para $22 \%$. As outras espécies, por sua vez, tiveram aumento de $4 \%$ para $7 \%$ no período (Figura 4).

Para esta grandeza também se observou diferença importante entre os resultados deste trabalho e aqueles informados no FRA2015 (FAO, 2014). A diferença do valor de 2016 deste estudo com o do FRA2015 é de cerca de $55 \%$, isto é, de 575 milhões $t$ neste $(569$ milhões $t$ em 2015) para de 891 milhões t no FRA, apesar da área menor utilizada naquela publicação e da diferença 
temporal.

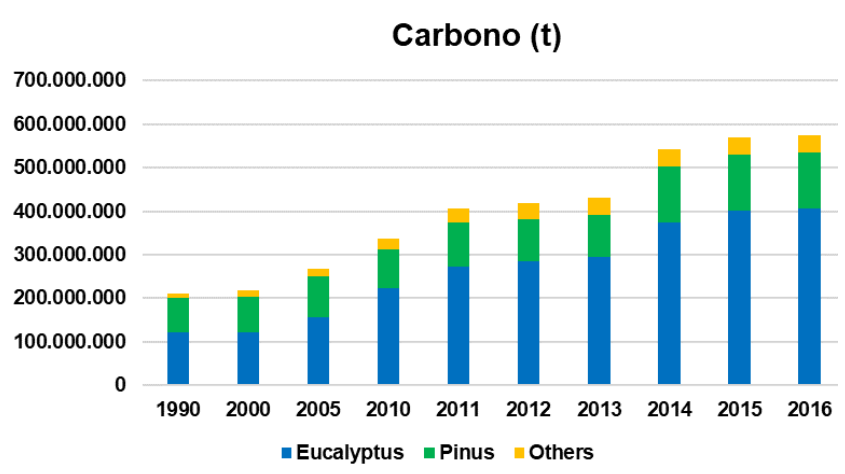

Figura 4. Carbono total estocado nas florestas plantadas do Brasil.

Os valores de estoque de carbono usados no FRA foram 96 e 19,20 t.ha ${ }^{-1}$, respectivamente para 0 compartimento acima do solo e abaixo do solo. Neste estudo os valores correspondentes foram 44,37 e 7,52 t.ha ${ }^{-1}$. As diferentes abordagens metodológicas são a causa dessa diferença, considerando obviamente valores mais elevados para os conversores de volumes para biomassa e carbono. Inclui-se no rol das diferenças a aplicação de outros valores de TC.

É importante considerar que as diferenças entre os valores calculados neste estudo e aqueles reportados no FRA devem ser analisadas com parcimônia, já que os valores de 2015 reportados pelo FRA são projeções feitas pelo menos um ano antes do referido ano, usando-se dados de anos anteriores. De fato, o FRA2015 foi publicado no ano de 2014 e os números mais atualizados neste estudo são para 2016. Portanto, há uma diferença temporal a se considerar.

O estoque total de carbono nas plantações florestais brasileiras corresponde à remoção de dióxido de carbono da ordem de 2,109 bilhões t $\mathrm{CO}_{2} e q$, aplicando-se as respectivas massas atômicas. A expansão da área plantada e o aumento das produtividades dos povoamentos proporcionaram a remoção de 4,905 bilhões $\mathrm{t} \mathrm{CO}_{2}$ eq. (1,338 bilhão $\left.\mathrm{t} C \times 44 / 12\right)$ no período 1990-2016.

Para se ter ideia da mitigação que essa remoção representa em termos efetivos, e considerando que 0 consumo de óleo diesel no Brasil em 2016 foi de 54 bilhões L (ANP, 2017), somente o crescimento das florestas plantadas no período considerado corresponde a 34 anos de todo o consumo desse combustível fóssil no País. Essa remoção também supera toda a emissão de GEE por mudança no uso da terra no País no ano de 2016, que é da ordem de 1,167 bilhões t $\mathrm{CO}_{2}$ eq (OBSERVATÓRIO DO CLIMA, 2018). Se considerado todo o estoque de carbono nas plantações florestais $(2,109$ bilhões $t$ C) a respectiva remoção seria de 7,733 bilhões $\mathrm{t} \mathrm{CO}_{2}$ eq, que superar todas as emissões de GEE do Brasil nos setores de energia e processos industriais de 2000 a 2016 (OBSERVATÓRIO DO CLIMA, 2018).

Neste cômputo de remoções de $\mathrm{CO}_{2}$ eq foi levado em consideração apenas o carbono estocado na biomassa, excluindo-se a necromassa e o carbono orgânico no solo. Tampouco se considerou as remoções equivalentes à estocagem em madeira e seus produtos nem a substituição de energia fóssil. O cálculo refere-se à remoção bruta em 26 anos, desconsiderando as emissões de GEE no processo de implantação e manejo dos povoamentos. Isso será alvo de trabalhos futuros.

\section{CONCLUSÕES}

Em 26 anos, houve expressivo crescimento nas áreas com florestas plantadas no Brasil. Esse crescimento se deu basicamente pela expansão da eucaliptocultura.

Houve crescimento de $158 \%$ no volume de madeira estocado nas florestas plantadas, de 774 milhões $\mathrm{m}^{3}$ para quase 2 bilhões $m^{3}$, aumento decorrente da expansão da área cultivada e da maior produtividade das florestas nos últimos anos.

O gênero Eucalyptus está em franco crescimento em todas as variáveis avaliadas e o Pinus participando em menor proporção da área plantada, quando comparado ao gênero anterior. Outras espécies têm participação modesta, mas em expansão.

Os estoques de biomassa e carbono aumentaram em torno de $170 \%$ em 26 anos e contribuíram para promover a remoção de 4,9 bilhão $t$ de dióxido de carbono da atmosfera. Essa remoção supera todas as emissões por mudança no uso da terra do País no ano de 2016 e todas as emissões de energia e processos industriais do País desde 1990, quando começaram a serem inventariadas.

Assim, as florestas plantadas, além de garantir o abastecimento doméstico e externo de produtos de madeira, também promovem a mitigação das mudanças climáticas.

\section{AGRADECIMENTOS}

À CAPES pelo suporte financeiro a este trabalho, por meio de bolsa de Pesquisador Estágio Sênior de PósDoutorado no Exterior junto à Universidade de Lisboa, Portugal, ao primeiro autor. Ao Dr. Joberto Veloso de Freitas, do Serviço Florestal Brasileiro, por realizar uma revisão no texto deste artigo. 


\section{REFERÊNCIAS}

ANP - AGÊNCIA NACIONAL DO PETRÓLEO, GÁS NATURAL E BIOCOMBUSTÍVEIS. Anuário Estatístico 2017. Brasília, 2017. Disponível em: http://www.anp.gov.br/wwwanp/publicacoes/ anuario-estatistico/3819-anuario-estatistico-2017

AGUIAR, D.R. et al. Estoque de carbono por grupo ecológico na Floresta Nacional do Tapajós. Revista Espacios, v.38, n.32, p.2134, 2017.

ALMEIDA, E.M. et al. Determinação do estoque de carbono em Teca (Tectona grandis L. F.) em diferentes idades. Ciência Florestal, v.20, n.4, p.559-568, 2010.

ANTONÂNGELO, A.; BACHA, C.J.C. As Fases da silvicultura no Brasil. Revista Brasileira de Economia, v.52, n.1, p.207-238, 1998.

BACHA, C.J.C. A situação atual dos dados sobre reflorestamento no Brasil. Análise Econômica, v.10, n.217, p.141-155, 1992.

$\mathrm{COHN}$, A.S. et al. Cattle ranching intensification in Brazil can reduce global greenhouse gas emissions by sparing land from deforestation. Proceedings of the National Academy of Sciences, v.111, n.20, p.7236-7241, 2014.

DALLAGNOL, F.S. et al. Teores de carbono de cinco espécies florestais e seus compartimentos. Floresta e Ambiente, v.18, n.4, p.410-416, 2011.

EMBRAPA - EMPRESA BRASILEIRA DE PESQUISA AGROPECUÁRIA. Softwares para manejo florestal. 2018. Disponível em: https://www.embrapa.br/florestas/transferencia -de-tecnologia/softwares-florestais

FAO - Food and Agriculture Organization of the United Nations. FRA2015 Brazil, Country Report. Rome: FAO, 2014.

HIGA, R.C.V. et al. Protocolo de medição e estimativa de biomassa e carbono. Embrapa Documentos 266, Embrapa: Colombo, 2014.

IBÁ - INSTITUTO BRASILEIRO DE ÁRVORES. Relatório 2017. São Paulo: IBÁ, 2017.

IBGE - INSTITUTO BRASILEIRO DE GEOGRAFIA E ESTATÍSTICA. PEVS - Produção da Extração Vegetal e da Silvicultura, 2016. Disponível https://sidra.ibge.gov.br/pesquisa/pevs/quadros/brasil/2016.

LERRER, D.; WILKINSON, L. Stora Enso e movimentos sociais: luta no campo e nas instituições. Estudos Sociedade e Agricultura, v.25, n.3, p.311-344, 2016.

NOGUEIRA, E.M. et al. Estimates of forest biomass in the Brazilian Amazon: new allometric equations and adjustments to biomass from wood-volume inventories. Forest Ecology and Management, v.256, p.1853-1867, 2008.

OBSERVATÓRIO DO CLIMA. Sistema de estimativas de emissões e remoções de gases de efeito estufa (SEEG). Disponível em: http://plataforma.seeg.eco.br/sectors/mudanca-de-uso-da- terra-e-floresta.

PAYN, T. et al. Changes in planted forests and future global implications. Forest Ecology and Management, v.352, p.57-67, 2015.

RIBEIRO, S.C. et al. Aboveground and belowground biomass and carbon estimates for clonal eucalyptus trees in southeast Brazil. Revista Árvore, v.39, n.2, p.353-363, 2015.

RIBEIRO, F.A.; ZANI FILHO, J. Variação da densidade básica da madeira em espécies/procedências de Eucalyptus spp. IPEF, n.46, p.76-85, 1993.

SANQUETTA, C.R. et al. Variação axial da massa específica básica de Acacia mearnsii em diferentes regiões do estado do Rio Grande do Sul. Revista Biociências, v.19, n.2, p.43-52, 2013.

SANQUETTA, C.R. et al. Estoques de biomassa e carbono em povoamentos de acácia negra em diferentes idades no Rio Grande do Sul. Scientia Forestalis, v.42, n.103, p.361-370, 2014.

SANQUETTA, C.R. et al. The role of forests in climate change. Quebracho - Revista de Ciencias Forestales, v.19, n.1-2, p.84-96, 2011a.

SANQUETTA, C.R. et al. Biomass expansion factor and root-toshoot ratio for Pinus in Brazil. Carbon Balance and Management, v.6, n.6, p.1-8, 2011b.

SANQUETTA, M.N.I. et al. Densidade da madeira e teor de carbono em indivíduos jovens de teca no Pará, Brasil. Científica, v.44, n.4, p.608-614, 2016.

SETTE JR, C.R. et al. captura de carbono orgânico em povoamentos de Pinus taeda L. na região de Rio Negrinho, SC. Floresta, v.36, n.1, p.33-44, 2006.

SFB - SERVIÇO FLORESTAL BRASILEIRO. O que é o Inventário Florestal Nacional. Brasília, 2017. Disponível em: http://www.florestal.gov.br/inventario-florestal-nacional.

SILVA, C.A. et al. Estoque de carbono na biomassa aérea florestal em plantações comerciais de Eucalyptus spp. Scientia Forestalis, v.43, n.105, p.135-146, 2015.

SILVA, H.F. et al. Estimativa do estoque de carbono por métodos indiretos em área de restauração florestal em Minas Gerais. Scientia Forestalis, v.43, n.108, p.943-953, 2015.

SILVEIRA, P. Estimativa da biomassa e carbono acima do solo em um fragmento de Floresta Ombrófila Densa utilizando o método da derivação do volume comercial. Floresta, v.40, n.4, p.789800, 2010.

SILVEIRA, P. et al. O estado da arte na estimativa de biomassa e carbono em formações florestais. Floresta, v.38, n.1, p.185-206, 2008. 